\title{
Learning experience design through Minecraft, Imagineering, and Storytelling
}

\author{
Roberto Razo, Manuel Siordia, Arturo García
}

Published: 30 November 2021

\begin{abstract}
The present research consists of implementing, through the learning experience design framework, a model that allows design students to connect the past with the present and the future of the profession. The process includes understanding the dimensions of the design of a historical character related to the discipline, implementing the hero's journey to tell his story but also contextualizing it in a three-dimensional environment in Minecraft. The video game allows them to express abstract elements in concrete through a three-dimensional representation that provides a user experience where you can also learn about these outstanding characters of the discipline.
\end{abstract}

\section{Keywords:}

Designers, Learning; Experience Design; Minecraft; Imagineers; Storytelling.

\section{Introduction}

A big challenge for teaching in newly admitted students in undergraduate design programs, is that they relate this concept with the creation and production of visual aesthetics elements, when designing is more related to the act of solving problems from characteristics and needs of an specific environment. In this way, knowing the context of a problem is an important process for discovering opportunity areas that could lead to a variety of solutions.

We wanted learning to depend not only from the student identity but also from the experiences he lived during the act of learning. For this we wanted to use Minecraft as a tool for creating information with context. Specifically for this project we wanted them to discover that any person can be an agent of change through design and that the impact of their work can be amplified in time, and to represent this by conceptualizing data and information in a $3 \mathrm{~d}$ virtual environment.

Razo, Roberto., Siordia, Manuel., García, Arturo.

Universidad Iberoamericana Puebla

Puebla, México.

roberto.razo.rodriguez@iberopuebla.mx,

manuel.siordia.aquino@iberopuebla.mx,

arturo.garcia2@iberopuebla.mx

\section{Problem Statement}

It is important to declare that the practice of design and the role of the designer have been decisive in solving complex problems. Complex problems are social problems that are difficult or practically impossible to solve due to various factors, such as the little information available on the matter and the interconnected nature of the problems with other problems [1].

Design students enter an institution of higher education with a superficial idea of what they will find in their classes. This skewed view is focused on the unique development of hard skills and the belief that it is all they need for their work life, as well as to fulfill their role as a designer. They consider that being a designer does not imply developing empathy with users, doing research or even pondering on the consequences of their actions. They fail to understand that the comprehension of design is not only in the production, distribution and consumption of objects [2].

\section{Background}

\subsection{Minecraft and its potential}

Minecraft is considered a perfect canvas for building worlds [3] given its classification as a sandbox game. These characteristics promoted it within classrooms around the world, and eventually led to the creation of an educational version that allows teachers and students to approach Minecraft as a teaching tool [4]. Those interactions are enriched with interactive processes such as the use of the item "redstone" for the creation of mechanisms and automation. This is complemented by a programming feature that allows the inclusion of non-playable characters (NPC) who can guide learning experiences as if they were part of a museum guide [5]. It is also worth noting the fact that the Minecraft education edition is already included in the Microsoft Office license that many students already have Minecraft is also of interest to us for its qualities as a virtual environment for cooperative and collaborative work. Allowing multiple users to connect synchronously to a world, build and communicate within it to achieve common goals [3].

\subsection{Design Dimensions}

An adaptation of the Design Thinking [6] phases was made to represent the dimensions that a designer must take into account during their work. The following dimensions were obtained after the adaptation: Context, Problem, Solutions, Decisions, Consequences and Products. 


\subsection{Hero's Journey}

The hero's journey was proposed by Joseph Campbell, said journey "is a common template that involves a hero who goes on an adventure, manages to be victorious in a decisive crisis and returns home changed or transformed" [7]. It was proposed that the students write a script about the trip of a famous designer taking into account the order of the following structure based upon Campbell's Seventeen Stages of a hero's journey [8] : Once upon a time, Every day..., But something was different/special about him..., One good day..., Consequences ...

The journey built with these guidelines should support the student to build an experience that can be perceived as a coherent and interesting story within the world of Minecraft for those who enter that world.

\subsection{Imagineers}

Walt Disney Imagineering is "the creative machinery that designs and builds all Disney parks, resorts, attractions and cruises around the world. They oversee the creative aspects of Disney games and products. " [9]. Disney elaborated an online course (Imagineering in a Box) that proposes to support those who want to enter this field. This course supports the student with resources that guide him in 3 main aspects [10]:

World Creation, Design of attractions and bringing the characters to life. Students were asked to focus primarily on the first lesson (World Creation), although they were not limited to reviewing the subsequent ones.

\subsection{Learning Experience Design}

The process of creating learning experiences that enable the learner to achieve the desired learning outcome in a human-centered and goal-oriented way. This process is projected in a canvas that contains the following elements: Learning outcomes, Learning objectives: Behavior, Insight, Skill, Knowledge, People, Characteristic, Strategy, Environment: Physical, Virtual, Social, Cultural., Location, Constraints, Resources, Activities, Process

\section{Design Process}

The learning experience canvas was used to relate the theoretical concepts with the learning intention with the following characteristics:

\subsection{Learning Outcomes}

Please The learning objective is a specific goal that you need to reach in order to achieve the desired learning outcome [11]. To this project it was to recognize the contributions of the main actors related to contemporary design through representing the dimensions of: context, problem, how they solve it, decision and consequences to acknowledge the impact their decisions had in the current context.

\subsection{Learning Objectives}

Other learning objectives related not only for knowledge and skills but also insights and positive behavior in students were:

1. To discover that any person can be an agent of change through design and that the impact of their work can be amplified in time,

2. The ability to visualize the impact that their decisions have in their own context.

3. The ability to transform and create 3 d digital environments in multi user virtual environments.

4. The ability to conceptualize data and information to create experiences in $3 \mathrm{~d}$ virtual environments.
5. To be aware of the impact of some design decisions in the past, the present and the future.

\subsection{People and Characteristics}

All the people that took part in the learning experience, 36 students and 3 professors of first semester of Interaction and Animation Design program in Puebla, México. This group of students were between the ages of 17 and 20 years, this means that they grew up having contact with Minecraft, released in 2009, since their adolescence. Another important characteristic of this group is that because of COVID 19, they had this first experience in a university context through digital environments and virtual classes.

We consider that using this resource was important because:

1. Is an affinity space that lets them relate serious topics with ludic environments.

2. Allow them to use tridimensional objects and spaces to contextualize content with legitimacy.

3. Let students use a virtual environment to represent a context that can be experienced and that is a result of real-life decisions.

4. Give the students a motivation to use affinity spaces to communicate legit content

\subsection{Environment}

An environment influences how we interact with each other and our surroundings [11]. For this course the main program we used to interact with students was Microsoft Teams as a virtual classroom. But specifically for this learning experience we choose to use Minecraft Education Edition which is also part of the Microsoft Educational Suite. Being a Multi User Virtual Environment, Minecraft has the characteristic to allow students to work online and create elements in a three dimensional representation. This environment uses cubes as the unit of representation. Through the assembly of these cubes, it is possible to make an abstract representation of real life environments. Minecraft becomes a space for social interaction that allows students to work in the same virtual space, letting them to change and edit its elements.

\subsection{Constraints}

The constraints referred to all limitations to the design, the realization and the implementation of a learning experience constraints can be challenging but they can also really boost your creativity using creative solutions to deal with these limitations will only make your design better [11]. The main constraint using this technology was the possibility to be online in the same virtual space. Problems with server connection can represent a moment of frustration because not every member of the team could be connected at the same time in the same space.

\subsection{Resources}

Minecraft Education Edition that is now available with the Microsoft academic account. This technology allows students to work without external server connection. They can all get connected to one of the participants' accounts that can display an environment saved in its account. This affordance was very important for our learning objective. We wanted students to work and create in a synchronic state.

\subsection{Process and strategy}

First students get information about the design phases and how design had to evolve through the following phases: naturalistic, inventive, and consumerist. These phases are often replicated when 
a design product is the result of an innovation process. After this, students have to visualize these concepts in Minecraft as: CaveNaturalistic, Farm-Inventive, Modern House-Consumerist.

After that the teacher gives a brief story of industrial and interaction design. How was the impact of design in the Industrial Revolution, the characters and how their decisions had an impact in the present way to do things.

He also shares some examples of people related to design and how they make an impact in their life and the consequences that his decisions have nowadays.

Then they received the following instructions: 1 . Choose a character related to design. 2.Create a story based on the hero's journey that can relate their context, problems, solutions, decisions, consequences and products, to the impact they have on the world. 3. Create a virtual space based using the imagineers principles.

\subsection{Activities}

Based on a character, student must develop the following information related to them: design dimensions, experience and land design from imagineers and hero's journey

With that information they had to produce the following documents:

- Script based telling a story of the characters life, based on the hero's journey.

- A 3D virtual environment in Minecraft Education edition based in the Imagineers experience design framework with its textual description.

- A video of the experience, recording all the pieces of the virtual ride and showing how the experience is supposed to be experimented by the user.

\section{Case Study}

The case study is a students work based in the life of Coco Channel, in which they gather information about the context of her life, select a problem which she had to give a solution and all the decisions she had to make.

\subsection{Their Land}

Then they define the following structure based in the imagineers design experience answering the following questions:

\section{Your own land}

What kind of land will you create?

Paris in the 1900, when Coco experienced the city to What is a story that takes place in this world?

The story is related to the design dimension and hero's journey and is expressed in the script.

\section{Theme}

How do you want users to feel about their experience in the world? Curiosity and empathy for the situation in which he was in the beginning and then emotion for what he achieves.

How do you imagine it feels to be inside your world?

You walk through a place full of mystery, class and luxury. Classic jazz songs sound

Channel 8 in the streets and parks, beautiful buildings

Europeans surround the viewer.

The area of the runway is wide, giving rise to imagination, the golden lion imposes admiration.

What do you imagine users learn from this experience?

In spite of the circumstances, do not limit yourself or do not close yourself off and look for a way to go back to what you are passionate about.
Nothing is impossible no matter how much it may seem; work for your goal and in time it will come

What lesson do you want to stay in the user's mind?

Inspiration / motivation to create, be it a new project or take up something that the user is passionate about

Layout Building design of Paris in 1883, 1990-1992, 1944 and now a days.

\section{Landscape, Materials, Graphics and Color}

This section sought to implement a touch of France to the world of Minecraft, to thus represent the experience that Coco Chanel lived in her native country, she also recovered the essence of the brand's catwalks with a lion and from the colors, a complete and clear atmosphere that would evolve over the years in the life of Coco (see Figure 1).

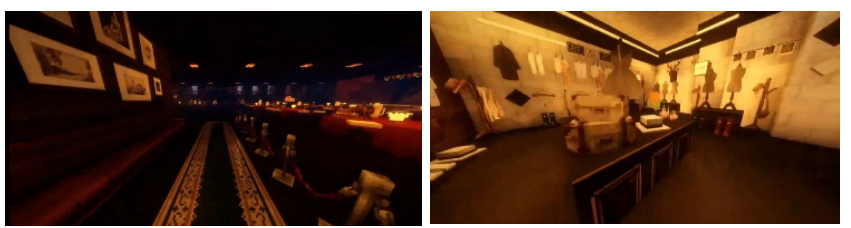

Figure 1. Life of Coco.

\subsection{Coco's Hero's Journey}

The story was elaborated in a timeline, in which all events have in themselves a consequence that leads to more events unfolding. This serves as one more guide detailed for our script, taking into account not only the key points but also the situations that presided over them.

1. Once upon a time, there was a girl who lived in a low-income family. 2. Every day she suffered because her parents could not support her. 3. When her mother passed away, she was abandoned in an orphanage. 4 . She was different from the others because she was very talented in fashion and sewing. 5. One day seeking financial independence, she begins to work. 6. One fine day she finds her first great love Étienne Balson thanks to her work.

7. Consequently, you have access to a great quality of life and contacts to whom you sell your hats. 8. Her partner did not support her with that business, and they separated. 9. Later he met Arthur Boy Capel who gave him all his support to open his first fashion store where he sold hats. 10. He gained a lot of popularity and thanks to that he began to add more types of garments to his collections. 11. He noticed the discomfort of women's clothing and focused on making them not only accessible and comfortable, but also sophisticated. 12. In 1921 he launched his fragrance Chanel No. 5. 13. Because of that, many people buy that fragrance, including Marilyn Monroe, who spoke highly of it.

14. As a result of that, your fragrance was very sold and continues to be so to this day.

15. In 1924 he added the "Tweed" dress to his collection, a simple and affordable dress for everyone. 16. Because of that, many women start wearing that dress and her name is all over the place once again. 17. But due to the war he disappeared from the public for a few years. 18. Until one day when he was 71 years old, he reopened his stores introducing the shoe of low heel. 19. As a result, women could look good and be comfortable once again. 20. Today these garments are indispensable and marked a revolution in fashion. Link to a video of the experience: $\underline{\text { Coco Chanel- Video }}$ DIA - YouTube 


\section{Results}

As a first observation of what happen after doing this exercise, we found out the following:

\section{Engagement and Motivation}

- Minecraft is a game that I have been watching since I was very young. Now it is introduced to education that is supposed to be a more serious model, I realized that it does not have to be that way, even the things that amuse me can help me contribute and learn a lot.

- That they take advantage of it and value the experience because it is worth having time with your friends learning things from someone that you probably did not recognize many things.

- In the digital world you can capture the most beautiful part of the classes and put them in a virtual world that you can call home. It is a kind of magic that no other games can achieve, you can build things that you know are close to you.

- It allows indirect coexistence in this coronaviruspandemic, it is not necessary to have a person nearby if you have the possibility to create such impressive things taking advantage of the current situation.

In words of one of the team students, this is the conclusion of their process: using the different approaches, this project revealed the most representative characteristics of Coco Chanel and in the same way, the journey of the artist's heroine, which led her to revolutionize the field of women's fashion in a time of war and repression. The experience in Minecraft managed to meet expectations and also explained the point of view of this fashion icon, since, within it, the user experienced the arduous path that Coco had to go through for its products to be successful. Regarding the learning and progress of the team, it was possible to experiment the arduous process necessary to design a story based on user experience, capable of provoking a reaction or teaching in the viewer. This taken up from the research process and the creation of an immersive world [12].

\subsection{Conclusions}

Through the planning and application of this learning experience, it was observed that the integration of technologies and chosen theoretical elements worked to accomplish the learning objectives, also the expectations regarding motivation, emotion and collaboration achieved by the students were surpassed. It was observed that compared to past occasions in live sessions, where a similar exercise was presented (without the integration of Minecraft, hero's journey and imagineers), the attitude, emotion and understanding on the part of the students was never very high.

Regarding the future of the project, an important aspect will be to consider implementing better and more instruments to evaluate the learning experience. It is also important to encourage the students to evaluate and test the effectiveness of the worlds they have proposed as teaching tools so that they can also reach conclusions about the effectiveness of the experiences they are proposing.

\section{References}

[1] Kolko, J. (2012). Wicked Problems: Problems Worth Solving: A Handbook \& A Call to Action. AC4D. https://wickedproblems.com/1_wicked_problems.phpMirand a, M. G. (2020). La diferencia entre diseñar y ejecutar. El diseño en los tiempos del copy-paste. Centro de Estudios en Diseño y Comunicación, 107-115.

[2] Vilchis Esquivel, L. d. C. (2020). Diseño, Investigación y Educación. Centro de Estudios en Diseño y Comunicación, 101-114.

[3] Ward Mather, L., \& Robinson, P. (2020). Durable Civic Technology: Minecraft as a Tool in Urban Planning Public Consultation. In C. Silva (Ed.), Citizen-Responsive Urban EPlanning: Recent Developments and Critical Perspectives (pp. 252-281). IGI Global. http://doi:10.4018/978-1-7998-40183.ch010

[4] Walton, M. (2015, February 22). Minecraft in education: How video games are teaching kids. GameSpot. https://www.gamespot.com/articles/minecraft-in-educationhow-video-games-are-teaching-kids/1100-6400549/.

[5] Microsoft. (2018). Download the code builder update to learn coding in minecraft: Minecraft education edition. Minecraft.https://education.minecraft.net/content/minecraftedu/language-masters/en-us/blog/download-the-codebuilder-update-to-learn-coding-in-minecraft.html.

[6] IDEO. (2011). Human centered design: Toolkit.

[7] Singh, M. (2019). The sympathetic plot, its psychological origins, and implications for the evolution of fiction. Emotion Review. https://doi.org/10.31219/osf.io/p8q7a

[8] Campbell, J. (2008). The hero with a thousand faces. New World Library.

[9] Disney Imaginations » Frequently Asked Questions. (2021). Retrieved 8 August 2021, from https://disneyimaginations.com/tips-faq/faq/

[10] Imagineering in a Box | Storytelling | Arts and humanities | Khan Academy. (2021). Retrieved 8 August 2021, from https://www.khanacademy.org/humanities/hassstorytelling/imagineering-in-a-box

[11] Shapers (2018, January, 27). Elements of the Learning Experience Canvas. Youtube. https://www.youtube.com/watch?v=ym0BGdHfEB8\&ab cha nnel=Shapers

[12] Carrasco, D. Mezo, V. Barón, S. Flores, L (2020). Diseño de Experiencia en Minecraft: Coco Chanel

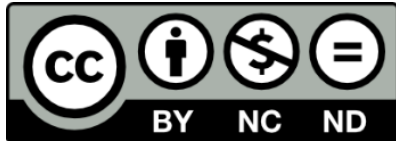

(C) 2021 by the authors. This work is licensed under the Creative Commons AttributionNonCommercial-NoDerivatives 4.0 International License. To view a copy of this license, visit http://creativecommons.org/licenses/by-nc-nd/4.0/ or send a letter to Creative Commons, PO Box 1866, Mountain View, CA 94042, USA. 